We thank Dr. Akhlaq R. Kidwai, head of the Chemistry Department, for providing facilities and also to the Council of Scientific and Industrial Research, India, for the award of a fellowship to one of us (R. H.).

WaHID U. MaLIK Rizwanul Haque

Department of Chemistry,

Muslim University, Aligarh, India.

${ }^{2}$ Boner, C. J., Indust. Eng. Chem., 29, 58 (1937)

${ }^{2}$ Lingane, J. J., and Kerlinger, H., Indust. Eng. Chem., Anal. Ed., 13, 77 (1941).

${ }^{3}$ Lewis, W. R., Quackenbush, F. W, and DeVries, T., Anal. Chem. 24, 762 (1949).

4 Lingane, J. J., and Laitinen, H. A., Indust. Eng. Chem., Anal. Ed. 11, 504 (1939).

'Elliott, S. B., The Alkaline-- Earth and Heavy Metal Soaps (Reinhold Pub. Corp., New York).

\section{4-Methyleneproline : Synthetic Studies}

Recentuy, Gray and Fowden have reported the isolation of a new amino-acid, 4-methylene proline (I), from seeds of loquat (Eriobotrya japonica). Structure (I) was firmly established by both chemical and spectroscopic evidence; but during the course of another investigation we have confirmed it by synthesis. This synthesis serves also to clarify some ambiguity concerning the optical configuration of the new amino-acid.<smiles>C=C1C[NH2+]C(C(=O)[O-])C1</smiles>

I
$\mathrm{O}$

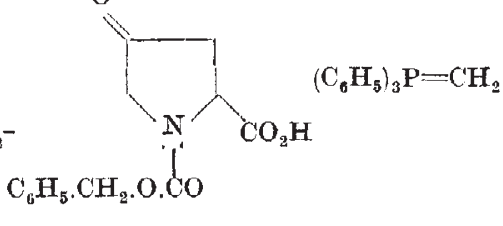

II

III
Wittig reaction ${ }^{2}$ between benzyloxycarbonyl-4oxo-L-proline (II) $)^{3}$ and methylenetriphenylphosphorane (III) yielded the oily benzyloxycarbonyl de. rivative of 4-methylene-L-proline. Its crystalline dicyclohexylamine salt had m.p. $160-161^{\circ}[\alpha]_{D}^{19^{\circ}-}$ $5.5^{\circ}$ (c. 2 in chloroform) (found: C, 70.89; H, 8.63; $\mathrm{N}$, 6.53. $\mathrm{C}_{28} \mathrm{H}_{38} \mathrm{O}_{4} \mathrm{~N}_{2}$ requires $\mathrm{C}, 70.55 ; \mathrm{H}, 8.65$; $\mathrm{N}, 6 \cdot 33$ per cent). The natural amino-acid, generously provided by Dr. L. Fowden, was converted into its benzyloxycarbonyl derivative by treatment with benzylchloroformate at $p \mathrm{H} \quad \mathbf{1 0 . 3}$ (autotitrator) in aqueous acetone; the dicyclohexylamine salt had m.p. $139^{\circ}$ and no detectable optical rotation in chloroform solution (found: $\mathrm{C}, 70.21 ; \mathrm{H}, 8.48 ; \mathrm{N}$, 6.63 per cent). In the solid state (nujol mulls) the two salts had distinctly different infra-red spectra, although the absorption bands corresponding to the principal functional groups were similar. In chloroform solution, however, the spectra were identical. Evidently the natural amino-acid is racemic, and this was confirmed by hydrogenation to a mixture of the cis- and trans-4-methylprolines (mainly the cis isomer $\left.{ }^{1}\right)$. We have shown previously that the optical rotations of the cis and trans isomers of 4-methyl$\mathrm{L}$-proline are both large and negative $\left(-85^{\circ}\right.$ and $-57^{\circ}$ respectivoly $)^{4}$. However, the hydrogenation product of the natural 4-methyleneproline had, within the limits of experimental error, no detectable rotation. and it can be concluded that less than 1 per cent of optically active material can be present.
4-Methyleneproline isolated from loquat seeds is therefore racemic, as suspected by Gray and Fowden ${ }^{5}$. This result is surprising, both in view of the rare occurrence of racemic amino-acids in Nature, and since the most plausible biogenetic precursor, 4methylene-glutamic acid, has already been isolated in an optically active form ${ }^{6}$, although from a different plant source.

Benzyloxycarbonyl-4-methylene-t-proline is a possible precursor for stereospecific synthesis of 4-hydroxymethylproline, the configuration of which is at present a matter of discussion?

\section{Marion Bethelt \\ G. W. KenNER \\ R. C. SHEPperi}

Department of Organic Chemistry,

University of Liverpool.

${ }^{1}$ Gray, D. O., and Fowden, L., Nature, 193, 1285 (1962).

2 Sehöllkopf, C., Angew. Chem., 71, 260 (1959).

${ }^{3}$ Patchett, A. A., and Witkop, B., J. Amer. Chem. Soc., 79, 189 (1957).

'Dalby, J. s., Kenner, G. W., and Sheppard, R. C., J. Chem. Sec. (in the press).

Fowden, L. (personal communication).

'Done, J., and Fowden, L., Biochem. J., 51, 451 (1952).

7 Biemann, K., Deffner, G. G. J., and Steward, F. C., Nature, 181, 380 (1961). Abrahan, R. J.', McT anchlan, K. A.', Dalby, J. S.', Kemer, G. W., Sheppard, R. C., and Burroughs, L. F., Nature,

\section{Use of Amines in Inorganic Hydrolysis}

FollowiNG the work of Smith and Page ${ }^{1}$, amines have been widely used for the extraction of acids from aqueous solutions. We have applied this process to the hydrolysis of inorganic salts in aqueous solution without the introduction of any reagents into the aqueous phase. An amine which is immiscible with the aqueous phase is used to extract the acid formed on the hydrolysis of the salt and under suitable conditions insoluble complexes can be precipitated. Thus comploxes of $\mathrm{UO}_{2}{ }^{++}, \mathrm{Th}^{4+}, \mathrm{Fe}^{3+}$ and $\mathrm{RuNO}^{3+}$ have been precipitated by us, and although the anion has usually been nitrate we have also carried out precipitations from sulphate media. Other anions could also be used since amines extract many acids efficiently (see, for example, Moore ${ }^{2}$ ).

The hydrolysis of uranyl nitrate can be made to proceed until a uranium complex is precipitated; for example, in a typical experiment when a $0.89 \mathrm{M}$ solution of uranyl nitrate in water was stirred with $0.5 \mathrm{M}$ trinonylamine (tri-3:5:5-trimethylhexylamine) in xylene for $5 \mathrm{~min}$. at room temperature a yellow precipitate was formed. After washing with water and drying at $60^{\circ} \mathrm{C}$. the composition of the solid corresponded to $\mathrm{UO}_{3} \cdot 2 \mathrm{H}_{2} \mathrm{O}$ (found: $U=73.2$ per cent, $\mathrm{H}_{2} \mathrm{O}=12.7$ per cent; calculated for $\mathrm{UO}_{3}$. $2 \mathrm{H}_{2} \mathrm{O}, U=73.8$ per cent, $\mathrm{H}_{2} \mathrm{O}=11.2$ per cent). The product was contaminated by xylene as shown by a carbon content of $0 \cdot 76$ per cent; but nitrogen could not be detected showing that no amine was present. The identity of the product was confirmed by X-ray examination and by differential thermal analysis (which indicated that it was the $\alpha$-form of $\left.\mathrm{UO}_{3} .2 \mathrm{H}_{2} \mathrm{O}\right)$.

The precipitated complexes are probably of the type $\mathrm{UO}_{3} \cdot 2 \mathrm{H}_{2} \mathrm{O} . x$ amine and thoir stability varies with the type of amine, for example, with a tertiary amine, such as trinonylamine, the amine can be removed by thorough washing followed by drying at $60^{\circ} \mathrm{C}$., but this is not the case if a primary amine such as 'Primene JM.T' (a proprietary mixture of alkyl primary amines with carbon chains ranging 